\title{
Art, Understanding, and Political Change
}

\author{
AMY MULLIN
}

Feminist artworks can be a resource in our attempt to understand individual identities as neither singular nor fixed, and in our related attempts both to theorize and to practice forms of connection to others that do not depend on shared identities. Engagement with these works has the potential to increase our critical social consciousness, making us more aware of oppression and privilege, and more committed to overcoming oppression.

In what follows, I argue that feminist artworks can be a resource ${ }^{1}$ in our attempt to understand individual identities as neither singular nor fixed, and in our related attempts both to theorize and practice forms of connection to others that do not depend on shared identities. Engagement with feminist works of art, particularly those that address multiple dimensions of individual and group identities, has the potential to increase what I will call, following Freire, our critical social consciousness, such that we can increasingly "identify societal power relationships of oppression and privilege and believe them transformable through resistant action" (Jennings 1995, 244).

In order to justify my claim that some feminist artworks can contribute to our understanding of the complexity of our own and others' selves and social locations, I need to do several things. I will (1) begin by giving examples of the kinds of feminist artworks which I find especially helpful in increasing this understanding, works that explore various ways in which women's diverse identities and social locations interact. I will next (2) explain why these works are feminist, but will also make it clear that these are not the only sorts of artworks I consider to be feminist.

After I give examples of feminist artworks and evaluate the extent to which they may be helpful in increasing critical social consciousness, I will then (3) explore the understanding of the self that was presupposed by my analysis.

Hypatia vol. 15, no. 3 (Summer 2000) (C) by Amy Mullin 
After I develop my own version of the socially constructed self, I will (4) give criteria for assessing methods for increasing social consciousness. Next, since I claim artworks can make a unique contribution to increasing critical social consciousness in virtue of their art character, I will (5) take issue with other prevailing conceptions of the nature of art. While I disagree with those that conceive of art as ideally entirely apart from the moral and political realms, my own understanding of the moral and political potential of art does not reduce the relationship between aesthetic and moral and political values to the conception of art as a pretty container for moral slogans. I will then (6) conclude with some questions and remarks about who the audience for the kinds of works I discuss might be.

In the third section of this essay, I will give an expanded account of the view of the self presupposed by my discussion of the following artworks. For now, I offer a preliminary sketch of this view, according to which each individual belongs to multiple groups. To the extent that we belong to multiple groups, and to the extent that these groups are all important in shaping who we are, even as we may resist them, we may be said to possess diverse socio-identities. Briefly, a socio-identity represents the perspective and life experiences of a group with which we importantly identify. Each of the works I examine in the following pages explores what it is like to be shaped by multiple and diverse socio-identities.

\section{FEMINIST ARTWORKS WHICH ADDRESS DIVERSE SOCIO-IDENTITIES}

Linda Gibson's Flag (1989) is one example of a feminist work that can serve to augment our understanding of the complexity of our own and others' socioidentities. In Flag, Gibson explores her ambivalence, as a young Black U.S. woman, towards United States patriotism. The film alternates among scenes of a Black woman and a white woman dancing with an altered version of a U.S. flag, voice-overs which give us biographical information about Gibson, images of flags, photographs of U.S. monuments, and aspects of mainstream patriotic American upbringing, such as the chanting of the Girl Scout oath.

Her work is clearly feminist in its integration of the personal and the social and in its exposure of society's gendered understanding of good behavior. She explores how a "good girl" is by implication white, and confronts the feelings of both pain and complicity that her self-interpretation as a "good little girl" brought her. Her work, especially in a scene where images of first Marilyn Monroe and then Angela Davis are superimposed on the photograph of a teenaged and smiling Gibson, suggests the pain and inner complexity involved when one's girlhood was spent admiring both Marilyn Monroe, an icon of passive white femininity, and Angela Davis, a Black radical. 
Throughout Flag, Gibson's diverse and shifting socio-identities as loyal American, woman, Black, radical, and feminist are traced and explored, as well as the emotions aroused by her sense of both belonging to and being alienated by U.S. society. For instance, Gibson clearly presents herself identifying with the flags variously displayed, burned, and altered throughout the film. She locates herself as not only shaped by North American culture, but also in some respects loyal to it, at the same time that she documents racist incidents from her childhood and her disagreement with many of the actions of her government. Because Gibson explores how she both belongs and does not belong to several social groups, her work stimulates those who view it to explore their own diverse social locations and to see how they may share some, but not all, aspects of Gibson's experiences.

In particular, viewers who share some of the middle-class North American aspects of Gibson's upbringing and identifications, but do not share her experiences of racism, alternate between experiences of recognition and alienation in responding to Gibson's work, in a manner that echoes Gibson's own alternation between a sense of belonging and a sense of being an outcast. Her work challenges its audience to explore our own loyalty and attachment to communities which may either appall us or reject us to varying degrees.

Jin-me Yoon, a Canadian artist born in Korea, is also interested in the intersection of various socio-identities. Yoon's focus, unlike Gibson's, is on how emigration, and the cultural displacement which follows it, impacts the construction of cultural identity. In her recent work Imagining communities (bojagi) $(1996)^{2}$ the central image is that of a bojagi, a square cloth which covers or wraps objects. Unlike a suitcase, which hides its contents within it, a bojagi covers but also takes on the shape of what it contains.

In this work, Yoon uses a number of bojagi to cover and therefore partially obscure viewers' access to folded screens, lightboxes, and photographs which contain images and Korean texts. The images are drawn from family albums and archival photographs, and blend the personal and the social. Their partially wrapped and obscured presentation suggests that the images take on multiple meanings based on the cultural location of the viewer. The audience is stimulated to explore alternate interpretations of what the images and texts may signify, and to hold none of these interpretations as definitive. Furthermore, the images are presented as not only of personal significance, but of public significance, while viewers are challenged to explore ways in which they feel connected to the domestic scenes presented, while also held at a distance from what they may mean. For instance, Yoon suggests that expectations of gender-appropriate behavior change as the emigrant takes on a new cultural location.

The web site accompanying the exhibit, in addition to presenting images, also asks the audience to comment on the concepts of home, family, commu- 
nity, nation, and citizenship. Here the artist insists on the political relevance of the supposedly private domestic sphere associated with women's place. In particular, she seeks to envision the possibility of creating a community of diasporic Korean women, all of whom experience continuities and discontinuities between their Korean background and their current location both geographically and culturally. Here it is important that Yoon does not suppose that such a community of women already exists, but explores how it may be created.

Carrie Mae Weems is a Black American artist. Mirror, Mirror (1987) is from her Ain't Jokin' (1987-88) series. ${ }^{3}$ These works confront their audience with racist jokes juxtaposed with portraits of simultaneously vulnerable and dignified Black men and women who are the butt of the jokes. The jokes are sometimes funny and always cruel, and, in the world outside of these artworks, are rarely made in the direct presence of their targets. Through this series, Weems hoped to reveal the extent to which racism has been internalized by Blacks and whites alike.

In Mirror, Mirror, a Black woman with African features stands before a mirror, implicitly asking "Who's the finest of them all?" The woman in the mirror, a Black woman with more typically white features, dressed in white gauze, and holding a kitschy magic wand, replies, "Snow White, You Black Bitch, and Don't You Forget it." On first sight, the photo suggests simply that the woman standing before the mirror has internalized and accepted the crudely punning racist words spoken by the mirror, and accepted the notion that beauty requires one to be "snow white." But, on closer examination, we notice the woman is not looking into the mirror but down and to the right. Has she, humiliated, submissively lowered her gaze? Or is she resisting the message of the mirror?

In this work, feminist concern with the way beauty and desirability are associated with repressive conceptions of femininity is enriched by an understanding of the way women of color are further haunted by associations between beauty, desirability, and whiteness in North American culture. But the work gives us no definitive message and does not dictate a response. It is openended and, if successful, initiates a series of questions and explorations on the part of its viewers.

Lorna Simpson, also a Black American artist, produced in 1986 two triptychs which accompany one another. The first triptych portrays three different images, nearly identical, of a Black woman, shown only from the waist down. She wears a plain white skirt, bare legs, white socks, and heavy, polished black shoes. In the first two images, her hands are clasped limply in her lap. In the third, she holds a small plastic boat, a child's bath toy. Her images have words superimposed upon them, reading, from left to right, "Marie said she/was from Montreal/ although." In the second triptych we are told "she was from haiti." 
This second set of three images portrays a dark, increasingly obscure background. ${ }^{4}$

Together, the works suggest that when white North Americans think a Black woman is from Haiti, her image is now dark and obscure. They give us reason to understand why the anonymous and yet particular young Black woman portrayed might claim instead to be from Montreal. But the work also suggests that the woman may well be from Montreal, or at least both Haiti and Montreal, and that North Americans have trouble accepting as "one of their own" a dark skinned woman if she hails from Haiti. The detail of the small plastic child's bath toy, in one of the images, also suggests that Marie may indeed have much in common with, as well as much that is not shared with, women raised only in North America, who may have less complicated socioidentities.

These works do not offer a clear-cut intellectual understanding of the nature of the conflicts and ambivalences women experience when they have diverse socio-identities. Nor do they offer a definitive response to such ills as the internalization of racist and sexist ideals. Instead they seek to make a connection with their audience and to explore the emotional consequences involved both in having diverse socio-identities, and in striving to make connections across lines of difference. Whether we, the members of their audience, have similar sets of diverse socio-identities or not, we can use our similarities as a starting point to explore our differences, as long as we also explore the possibility that what we find familiar and comfortable, and what we suppose we share with others, may obscure important differences. What we may share may be the experience of having diverse socio-identities, even if both the various socio-identities themselves, and the way we negotiate the conflicts between them, may differ profoundly.

Jamelie Hassan is a Canadian woman of Lebanese background. Her installations, such as Meeting Nasser (1985-86), The Copyist (1995), and Aldin's Gift (1996), often combine photographic elements with ceramics and texts in English and Arabic. The coexistence of the different visual media and the different languages, along with the initial alienation members of her audience may feel upon being confronted with combinations of different elements, stimulates awareness of the multiplicity of socio-identities and of our expectations that identities be either "foreign" or our own, and not both simultaneously. For instance, do those of us who are not Arabic dismiss her work as not capable of speaking to us? What does it mean that she uses both Arabic and English? In Hassan's works, which often examine the relations between immigrant mothers and their children, the artist's identifications with Canadians, immigrants, Arabs, and women are explored in relation to one another, and she challenges her audience to explore the ways in which they connect and fail to connect to the identifications she explores. Moreover, in all of her 
works, women are seen as political agents, and the sort of "women's work" associated with raising children is seen as being of vital political significance.

Yolanda López produced three works (out of an envisioned five) which together are often referred to as The Guadalupe Triptych (1975-78). In these works, which portray first López, then her mother and her grandmother as the revered Virgen de Guadalupe, López not only confronts her diverse socioidentities as Chicana, as feminist, and as Catholic woman, but also works at reintegrating, in various ways, those fragmented and conflicting identifications.

As Annette Stott observes, "Historically, both church and Mexican-American society have promoted the Virgin of Guadalupe as a model of female behavior and identity. Cloaked in a star-spangled cape with her eyes demurely downcast, the Guadalupe traditionally stands on a black crescent moon against a radiant sun, upheld by a small boy angel" (56). By contrast, López's first figure is anything but demure. While she retains the star spangled banner and the radiant sun, this Guadalupe also carries a snake, a Mexican symbol of self-knowledge and sexuality. Moreover, she is strong, athletic, and gazes directly at her audience. She is, perhaps, supported by the small boy angel underneath her feet but seems, somewhat disturbingly, to tread upon him. ${ }^{5}$

The other two images present the Guadalupe first as López's mother, gazing directly at the audience, resting briefly from her work sewing the starry cape, and then as her grandmother, again with a direct stare, skinning a snake. All three are active, but in each the various symbols representing the Catholic church, a Mexican heritage, and self-knowledge are presented in a different relationship to one another-with none of these relationships, however, privileged as superior to the other. For instance, in the portrait of her mother, the snake is tightly coiled around the sewing machine and the small boy angel seems protected by the cape the mother sews. Each woman is presented as complex, working out in her own way a negotiation between her various socioidentities.

One of the strengths of these works is the way in which they emphasize that women can have much in common and yet also have experiences very different from one another. For instance, white South African artist Jane Alexander shows us both what connects and what distinguishes three women in her sculpture Pastoral Scene (1985). The women are divided by age, race, and class. One, the white woman, stands and offers up an inadequate amount of food to the other two, who are both Black and seated on a bench. Of the two women on the bench, one is dressed to clean house, and the other breastfeeds a child. The women have different amounts of power in relation to each other (the white woman stands and is in a position to offer food to the others), but they are connected in both their nurturing activities and their expressions of exhaustion.

Alexander's work, like that of Gibson, Yoon, Weems, Simpson, Hassan, and López, explores tensions that arise from identifications with multiple and 
sometimes conflicting communities. These works explore both the pain and the promise of intergroup dialogue, and confront together some of the multiple causes of oppression. They do this while challenging some of their audience's comfortable assumptions about who they are and what communities they belong to, but also while providing those same audiences with experiences which delight, frustrate, and stimulate them. Because the works give pleasure in their formal properties and in the way the stimulate their audiences' imaginations, they can motivate their audiences to explore, in openended ways, their own and others' complicated and sometimes conflicted identifications with a variety of social groups. Moreover, communication across lines of difference is made possible, but, at the same time, the artists indicate that complete understanding will not be possible-as suggested by Yoon's partially obscured images and Hassan's use of multiple languages.

All of the above-mentioned works explore diverse socio-identities. Gibson, Yoon, Weems, Simpson, López, and Hassan, along with other feminist artists including Yong Soon Min, Lorraine O'Grady, Claire Carew, Jolene Rickard, Coco Fusco, Adrian Piper, and Martha Rosler, explore the complexity of an individual's group affiliations. Their work urges us to recognize this fluidity and multiplicity both in ourselves and, perhaps more crucially, in others. For example, a work by Canadian artist Claire Carew, Here I Stand (1989), ${ }^{6}$ portrays and salutes her Aboriginal, African, and European ancestors. She refuses to limit herself to identification with only one group, and she challenges her audience to rethink their own relations to those they regard as ancestors.

\section{What CONSTItUTES FeMinist ART}

These feminist artists combine a focus on socio-identities dependent on gender and sex with an examination and exploration of other aspects of a person's identity and social identifications. Their work suggests that we cannot separate one aspect of a person's identity, such as her sex, from her other socioidentities, and that sexual oppression is experienced differently depending on those socio-identities. All are making feminist art, in that they focus on sex or gender and work towards politically progressive social change. They integrate the personal and the social, and present both as politically significant. They expose gender stereotypes and gendered expectations. They seek also to envision alternatives to oppressive social practices. In these respects, they have much in common with other feminist artists.

I should observe here that, strictly speaking, we can assess whether or not a work of art is feminist only by understanding how it is received by its audience or audiences. An artist cannot be sure whether his or her work is feminist on the basis of the artist's intention alone. Whether or not the work is feminist will also depend upon what sort of audience it reaches, and on the impact it has. My claims, throughout this essay, that certain works of art are feminist 
reflects both their impact on me and my assessment that the works have the potential to have a similar impact on others. However, as I go on to discuss in the fifth section of this essay, we cannot predict where the imaginative explorations prompted by artworks will take us or others.

Due to frequent misunderstanding of the nature of feminism in the arts, I need briefly to observe that, like feminism itself, which is united in its opposition to sexual oppression but diverse in its understandings of the causes of that oppression and the best strategies for opposing it, feminism in the arts is heterogeneous. Feminism in the arts should not be confused with essentialist assumptions about the existence of a feminine style of art-making (Vogel 1988).

It might be thought, instead, that feminist art practices are characterized by an uniquely feminist style of art-making. There is some debate within feminist art theorizing on this topic. Peggy Brand offers a rare defense of the notion that artworks may be identified as feminist based on their formal properties. Her view is complicated by her insistence that these formal properties must be seen as "indications of a viewpoint" which is feminist in virtue of seeking to restore dignity and pride in the accomplishments of female artists. (Brand 1995, 267)

While several of the artists I mentioned above often work in a style that combines photographic elements with texts, each also operates in a variety of styles. Moreover, other artists—and advertisers, too, for that matter-also use a style which combines visual elements with texts, with both different intents and different results. Most feminists working within the arts reject the notion of a peculiarly feminist style of art-making, if style is understood as referring solely or chiefly to formal properties of the artwork.

The majority of feminist art theorists warn of the dangers of assuming that certain styles (for example, realism) are either suited to or inappropriate for feminist art production (Rich 1990; Marcus 1992; de Lauretis 1990; Felski 1995). As Felski succinctly puts it, "there is no longer any necessary connection between symbolic transgression and political transgression, between stylistic rupture and processes of social change" (Felski 1995, 439). Instead, a work of art is feminist when it focuses on sex or gender and works towards overcoming stereotypes and oppression.

Feminist artists are both critical and constructive in their explorations of gender stereotypes and experiences of sexual oppression. Some works, like U.S. artist Hannah Wilke's Hannah Wilke: Super-T-Art (1974-76), seek chiefly to expose the impact of gendered expectations on women. In a series of photographs, the artist drapes herself in a sheet in distinct ways that suggest woman as muse, woman as pin-up, woman as supplicant, and woman as crucified Christ. Other artists, like Canadian Nina Levitt, in works including Submerged (for Alice Austen) (1991) and Le Monde Interdit (1992), seek also to envision alternatives to stereotyped and oppressive social practices. Levitt not 
only exposes the hysteria involved in stereotypes of lesbian identity, she also presents alternative images of women connecting to one another emotionally and physically, particularly through her repeated selection of images of women holding hands from historical photographs.

As is the case with Levitt, and with all the artists I discussed above, feminist artists frequently combine their exploration of sexual identities and oppression with an exposé and exploration of other forms of identities and oppression. In particular, these works urge us to acknowledge the ways in which various aspects of a woman's identity and social location intersect. They suggest that what is regarded as appropriate for a woman varies with her race, class, age, sexual orientation, and health, and that we therefore cannot separate opposition to sexist oppression from attempts to eliminate other forms of domination.

All of the examples I discussed were drawn from the visual arts. However, I am not claiming that the visual arts are more likely to achieve these goals than other art forms. It is important to note, moreover, that feminist artists are often marked by both their combinations of and departures from various traditional visual media. Moreover, while the feminist artists I discussed were in all cases women, I am not claiming that only women can be feminist artists. Just as whites can be opposed to racism, so can men be opposed to sexism, and men can make feminist art or be feminist artists. Jack Butler's work Genital Embryogenesis (1993), which blends science and art to suggest that all bodies start in a state of sexual indifference, and that it is society, not nature, that favors men over women, is a work of feminist art. However, just as whites need to beware of focusing more on the way all people are damaged by racism than on their position of privilege, so, too, feminist men need to be wary of focusing only on the way men are damaged and distorted by gender stereotypes.

While some may wonder whether other artworks, which are not specifically feminist, may also work to increase critical social consciousness, I am not concerned in this paper to argue that works of art which do not focus on sex and gender (and which therefore could not be feminist) could not also contribute to such an increase. Certainly works of art which were sexist, like works that were racist or classist, and hence reinforced oppressive practices, could also enhance critical social consciousness by serving as objects for analysis. This would require us to bring an independent awareness of the existence of sexism and/or other forms of oppression to the works. The works could then be studied to offer us insight into the processes involved in developing and spreading these forms of oppression.

Moreover, other activist artwork not specifically focused on sex or gender, which addressed persons' complicated and sometimes conflicting identifications with social groups in ways which did not present either the identifications or the groups as fixed and static, could also increase critical social conscious- 
ness through increasing understanding of the diverse nature of both the self and others. It is sufficient for my purposes to note that, since our identities which reflect sex and gender are both so important, and have such an impact on our other group identifications, feminist artworks make a unique contribution to the above-mentioned goals. Moreover, feminism's commitment to integrating understanding of the personal and the social contributes directly to these goals.

\section{UNDERSTANDING THE SELF AND THE IMPACT OF GROUP MEMBERSHIPS ON IDENTITY}

Having now provided examples of feminist artworks which address multiple socio-identities, and having briefly discussed why these works should be considered feminist, I may now turn to the task of developing my previously promised account of the nature of the self. Throughout this essay, I operate with an understanding of selves as crucially, though not exclusively, shaped by their social experiences, in particular by their group affiliations. These affiliations include membership in groups which are chosen, and membership in groups which may be welcomed or resisted but into which we are placed by others without our consent. The latter include groups based on race, sex, age, and ethnicity. The former include groups based on profession or shared values, including a commitment to feminism.

To the extent that we belong to multiple groups, and to the extent that these groups are important in shaping who we are, even as we may resist them, we are internally not multiple but heterogeneous. Following Elisha Babad, Max Birnbaum, and Kenneth Benne's terminology in The Social Self (1983), I speak in this paper of each person as shaped by diverse socio-identities. The latter are similar to roles, in that they are group affiliations accompanied by expectations both by the self and others for appropriate behavior, but they are more broadly defined. A socio-identity represents the perspective and life experiences of a group with which we importantly identify.

While I assume in this paper that socio-identities are plural, I want to avoid models which depict people as composed of multiple little selves, in which each socio-identity is seen as itself fixed. I have discussed the dangers and the limitations of these models elsewhere, ${ }^{7}$ but most basically they err in assuming that both communities and our ties to them are fixed and homogeneous. They limit our options for understanding how to resolve differences, both within the person and between groups, to (a) suppression of one or more social groups or socio-identities; (b) compartmentalization or separation of the different groups or socio-identities with no real understanding of or interactions between one another; and (c) negotiation of difference, but with the unfortunate assumption that no social group or socio-identity is capable of change. 
In the first case, a woman would be supposed to have to choose between her loyalty to her racial group, for instance, and her loyalty to her sex. This kind of choice suggests that her racial group is necessarily only concerned with issues affecting men of that race, and that the community of women is not concerned with issues affecting women of her race. ${ }^{8}$ In the second case, a woman could alternate between activities with one group and activities with another, but the groups would still be conceived in this limited and homogeneous way. In the third case, a woman might participate in the negotiations between one group and another, who may sometimes share an agenda. However, the groups and the identifications with them that structure her identity would not be seen as open to change. Neither she nor they would recognize that the groups as they stand require at least some of their members to bifurcate themselves, and to suppress other aspects of their identity.

Instead, I believe it can help to think of socio-identities and their relationship to personal identity on the model of an individual's relations to his or her parents. We are born into many of the groups that form our socio-identities. But, just as we may be born to parents, adopted by them, or become someone's child as a result of one parent's choice to acquire a new partner, so too may socio-identities be the result of personal choices, twists of fate, and life experiences rather than birth.

Our parents may hold equal or unequal power, both in relation to each other and in relation to us. So, too, may the groups with which we importantly identify be of equal or unequal power, both in relation to one another and in relation to their hold over us. Our parents may change their values or beliefs or patterns of behavior over time. We may welcome or resist those changes. So too, may both the groups to which we belong and our own internalization of those groups change over time, in ways we welcome and ways we resist. Finally, just as we are not expected to be clones of one or both or all of our parents, we should not be expected to be "representative" of our groups. This does not, of course, mean that we are not influenced by and attached to our parents and our groups in various ways.

Understanding our own diverse group affiliations can help us to understand others, and not simply those who share our group affiliations. As a result, it can lead towards working with others towards more pluralistic forms of social heterogeneity, that is, more political, economic and social equality. An understanding of our own diverse socio-identities, and the way they affect how we feel, behave, and are treated, makes us conscious of the way group affiliations operate more or less unconsciously in our dealings with others. When we understand, also, that other people may have multiple group affiliations and diverse socio-identities, this can minimize our tendency to stereotype others, particularly those whose group affiliations are different from our own. This is most clearly the case when we see how our own socio-identities can be in 
tension or outright conflict with one another, and how one social group we may belong to may publicly or privately discriminate against or stereotype members of another group to which we also belong. This kind of understanding can also reduce our tendency to think of others, including those who do not share our group affiliations, as one-dimensional.

\section{METHOD FOR INCREASING CRITICAL SOCIAL CONSCIOUSNESS}

Understanding of our own heterogeneity and its social roots can therefore be both supported by and supportive of our attempts to understand and respect others' differences. Moreover, "empathic understanding across lines of social cleavage is extremely important in achieving pluralistic solutions to intergroup problems" (Babad, Birnbaum, and Benne 1983, 43). As the authors observe, this can be difficult to achieve when people have different socio-identities, but people's ability to empathize ${ }^{9}$ can be increased. The authors cited above suggest a method of training which focuses on social influences and their impact through self-inquiry and understanding of the group dimensions of one's own life history, and through understanding of the barriers to this type of knowledge (such as defensiveness, stereotyping, distorted self-justification, resistance to change, and the role of the media). This kind of training aims to arrive at what Paolo Freire, and others committed to socially conscious pedagogy, call critical social consciousness (Freire 1973).

In what follows I will describe their criteria for assessing methods for increasing one's critical social consciousness ${ }^{10}$ and offer an analysis according to which feminist artworks can help to achieve some of the same goals. But first I would like to offer some remarks explaining why I find their research useful. In this essay I assume that the self is socially constructed. Babad, Birnbaum, and Benne work within the field of social identity theory and, unlike some other theorists with a social constructivist view of the self, do not make the mistake of viewing the society which shapes the self as unified or unitary. Mead, for instance, believes that we are only fully developed as selves once we have internalized the "social attitudes of the generalized other or the social group as a whole" to which we belong (Mead 1962,158). We are each seen to belong to one and only one social group, and this social group is itself thought to be homogenous $(1962,144)$.

Another virtue of Babad and colleagues, in my estimation, is that while they view the self as socially constructed, they do not view the self as socially determined. A socio-identity is an individual's internalization of and response to one of her group memberships. It is not a "subject-position" into which she is inscribed by a discourse. ${ }^{11}$ Selves are still capable of agency, although the very competencies that are exercised in agency can be thwarted or encouraged by social factors. 
Finally, while feminist epistemologists and others have given us good reason to be wary of reliance on social scientific "expertise," for the supposed experts are often, if unknowingly, complicit with the dominant and oppressive groups within a society, we would also be unwise to dismiss the theorizing of social scientists who are committed to social justice and to overcoming oppression. ${ }^{12}$

There are several important subfields within psychological research which are committed to developing psychological theories that increase critical social consciousness. The work of Babad, Birnbaum, and Benne is in harmony with and systematizes the similar work being done by other social scientists committed to increasing critical social consciousness, particularly in their emphasis on the need for the privileged to see themselves, and not just the oppressed, as socially located. ${ }^{13}$ Here it is also important that those who have developed these theories are often themselves possessors of diverse socio-identities, including identities associated with oppressed social groups.

The method Babad, Birnbaum, and Benne suggest combines self-inquiry with intensive work with groups who are as diverse as possible along as many dimensions of difference as possible. I am not arguing that exposure to artworks can obviate the need for more personal contact with others and work with groups, particularly diverse groups. ${ }^{14} \mathrm{I}$ am instead suggesting that exposure to feminist artworks which address or express diverse socio-identities can help people gain an understanding of both themselves and of others that can motivate them to work with others across lines of difference with an aim of achieving a more pluralistic society. Moreover, given that contact with others' artworks is a form of contact with those persons and their expressions, albeit a mediated contact, it can provide those who interact receptively with the artworks with some understanding of other cultures and other people, which might facilitate interactions with others and therefore coalition building. It may also, as I will discuss later in my paper, help prepare us for more sensitive direct encounters than we might have had in the absence of exposure to the artworks. This is because artworks of the above-mentioned type can foster understanding of both the similarities and the crucial differences in the experience of those whose socio-identities are different from our own.

Babad, Birnbaum, and Benne provide a list of "the requirements for a productive method of inquiry into the social self" $(1983,38)$. The seven criteria are:

(1) The method must increase the persons' awareness and acceptance of the heterogeneity of society and its resulting personal and social difficulties.

(2) It must draw upon scientific social-psychological knowledge and show its relevance and applicability to learners' life situations.

(3) It must challenge and support persons to become aware of their own unarticulated personal knowledge and underlying psychological theories. 
(4) It must help learners to become aware of the obstacles to self-inquiry and to circumvent them where possible.

(5) It must help persons to understand the socio-cultural genesis of group differences and to empathize with others of distinctive perspectives and ways of life.

(6) It must help persons to recognize the major psychological manifestations of intergroup process (such as group unity and cohesion, stereotyping, prejudice, and discrimination) and to examine how these phenomena are reflected in their own life-events.

(7) It must help persons to practice pluralistic ways of dealing and working with persons different from themselves. (1983, 38-39)

In what follows I am not going to argue that exposure to feminist artworks meets the authors' second criterion, that of drawing upon scientific social science, although of course in some cases the artists in question do draw upon such knowledge, either through direct consultation or through their own study. For instance, in producing her works dealing with domestic violence, artist Peggy Diggs read extensively in sociology and psychology, and consulted experts in these and the medical professions. The works which resulted include Objects of Abuse (1991), Memorial (1991), and The Domestic Violence Milkcarton Project (1992). She also had long conversations with victims of domestic abuse. Similarly, in her preparation for the Hartford Grandmothers Project (1993-94), while she began by reading about crime and the aged, she proceeded to spend almost a year interviewing elderly women from a variety of economic and ethnic backgrounds (Phillips 1995).

The extent to which Diggs supplements her readings in social science with actual contact and consultation with the diverse subjects of that expertise points to the dangers of more simple reliance on scientific knowledge. As I argued above, supposedly expert scientific knowledge may itself be infected by shared sexist or racist biases of the experts, particularly where the community of expert knowers is neither itself diverse nor open to criticism from without (Antony 1993; Longino 1993). Therefore, while feminist artists do not always meet the authors' second criterion, this may sometimes be a source of their strength.

Exposure to types of feminist artwork which address multiple socio-identities can meet the authors' other criteria-most noticeably the first, fifth, and sixth. It is important to remember, however, that meeting these criteria means only that exposure to feminist artworks potentially increases people's awareness and acceptance of personal and social heterogeneity. They are only one step on the path towards further such awareness and acceptance.

When we respond receptively to these artworks we increase our awareness of the heterogeneity of society. The works I discussed explore the tensions involved in multiple group affiliations, and explore the different ways we can 
respond to our diverse socio-identities (criterion 1). Through their expression of the emotions felt by persons with conflicting socio-identities they may also help us empathize with others of "distinct perspectives and ways of life" without ignoring the ways in which they differ from us (criterion 5). The works often also document the way important inter-group processes, such as the internalized racism explored by Gibson and Weems, impact on an individual's experiences and sense of self (criterion 6). Through providing us with an opportunity to respond receptively to someone who is both similar to and different from ourselves (in which ways we are similar and different depends upon each person's individual socio-identities and how they differ from those expressed or explored in the work), they also help us practice pluralistic ways of dealing with people significantly different from ourselves (criterion 7).

\section{ART THEORIES}

It is still, unfortunately, controversial in art theory to claim that we can learn from art, particularly if we do not mean that the learning is incidental to the experience of the work as art. It is even more controversial to claim that our experience of art can have moral and/or political significance. Even when it is accepted that art can have a moral dimension, most critics remain "moderate autonomists," asserting both that "the categories of moral and aesthetic criticism always are conceptually different from one another" and that "it is never the moral part of the criticism that diminishes or strengthens value of an artwork" (Anderson and Dean 1998, 150). Radical autonomism goes even further in repudiating connections between art and knowledge, morality, and politics in that because art is thought to be "distinct from other social realms which pursue cognitive, political or moral value ... it is inappropriate or even incoherent to assess artworks in terms of their consequences for cognition, morality and politics" (Carroll 1996, 224). For autonomists it is the design of the artwork, not its content, that is the proper object of our aesthetic absorption. If the content is too obtrusive, it may distract from our experience of the object as a work of art.

Moreover, both moderate and radical autonomists tend to assume that whatever is morally, politically, or epistemically significant about an artwork must be conceived as content, understood as a series of lessons or propositions. They do not consider that a work of art may seek to initiate a dialogue with a receptive audience, or explore ambivalences. It is rarely acknowledged that artworks may be of moral or political significance because of the ways they challenge and stimulate our imagination. ${ }^{15}$ Yet the works I examined do just this.

As a result, even those theories that acknowledge that a work of art may be evaluated morally, as well as aesthetically, miss the unique contribution that 
artworks may make in initiating an encounter in which we are receptive to the work in a non-rulebound manner. As I will discuss later in the paper, artworks, including feminist artworks, are valuable because of the way we respond to art with our senses, emotions, imagination, and understanding, all in interplay. A feminist artwork is not separable into two distinct aspects: an artwork, which provokes a purely sensuous response, and a political lesson, which we cognitively process. All of the aspects of the work, its formal properties, the emotions it invokes, and the ideas it suggests, work together.

Feminist art theories necessarily suppose that art, knowledge, and politics are connected in deep and important ways. Otherwise there would be no reason to have art theories that are specifically feminist. They are therefore opposed to autonomist, or formalist, understandings of the nature of art as sketched above. According to formalists such as Immanuel Kant, Clement Greenberg, Clive Bell, and Roger Fry, artists are individual geniuses whose works could and should serve no social function. Reception of artwork is required to be disinterested, and aesthetic absorption occurs only when we focus solely on the formal properties of a work.

Feminist art theorists are not unique in opposing autonomist art theories. Institutional art theories such as those of Danto and Dickie, critical cultural theories such as those of Adorno and Benjamin, and the theoretical perspectives of Rorty, Margolis, and Shusterman all oppose some features of formalist art theory. ${ }^{16}$ Feminist art theories overlap in some respects with other theories which oppose an understanding of art as autonomous. What makes them specifically feminist is their emphasis on and critique of formalist art theories' implications for sex and gender. Thus, for instance, they expose the extent to which the audience for art is claimed to be universal, but tacitly supposed to be white, well-off, and well-educated in the theories and accomplishments of men in the United States and western Europe. They seek to avoid romanticizing the notion of the individual genius artist, in favor of recognizing that artists' visions are shaped by their social circumstances and contacts. The art theories of Peter Lewis, Matthew Kieran, and Noel Carroll all suggest that response to art involves the emotions, understanding, and imagination. As a result, their theories, while not specifically feminist, can help us understand how feminist artworks function. The work of Martha Nussbaum incorporates many of these insights in the service of a more specifically egalitarian and feminist vision. In the remainder of this section I will discuss first the work of Lewis, Kieran, and Carroll, and then the theories of Nussbaum.

It is the way art simultaneously engages our imaginations, emotions, bodies, and intellects that makes it uniquely suited to affect us more deeply than other, more purely intellectual, ways of conveying these ideas. As Matthew Kieran puts it, it is "through what we imagine and the promotion of imaginative understanding in engaging with artworks that art may justifiably lay claim to the cultivation of our moral sensibilities" (Kieran 1996, 337). Kieran views art 
as increasing what he calls our imaginative understanding, which involves our attempt to grasp how we should respond to the world, including how we should feel about and respond to others $(1996,341)$. Artworks do not simply give us information, but they help us explore our beliefs, values, and feelings about ourselves, others, and the world. They absorb us by stimulating our imaginative understanding, not by making statements that could be paraphrased (Kieran 1995). Each work, therefore, leads to an unique encounter.

Kieran tends to suggest, however, that artworks prescribe and promote one particular imaginative understanding of the world. He therefore finds a work like Leni Riefenstahl's Triumph of the Will to be of "artistic disvalue to the extent that it promotes a fundamentally false imaginative understanding of its subject" $(1996,347)$. He finds other works, like Charles Dickens's Hard Times, aesthetically valuable for (among other reasons) the particular imaginative understanding they produce. By contrast, I think Kieran sometimes makes the association between the imagination and the understanding too strong. I do not think we can be so sure as to the kind of understanding any one person's imaginative engagement with a work will promote.

While I believe there are no essential properties, formal or otherwise, that all and only all artworks share, I do believe that we respond to what have been identified as artworks in similar ways, partly because of conventions of the artworld, partly because of the functions we expect artworks to serve, and partly because of the complex character of the works themselves. We are often prepared to linger, to be absorbed, to be receptive to the work and its impact on us, without expecting any immediate response. This detachment from the need to respond immediately (either with action, or with a judgment about the value of the work) does not mean detachment from interest.

Moreover, when we respond to artworks we respond on many levels, and our emotional response cannot be separated from the way the work stimulates our imagination and contributes to our understanding. As Noel Carroll argues, sometimes we cannot even understand a work unless we respond to it in an emotionally appropriate way (Carroll 1996). Moreover, all emotions have a cognitive component; something in the world is recognized as having features that are scary or soothing, for instance, and our emotions can in turn suggest ideas and understandings.

Peter Lewis, in his development and defense of Collingwood's theory of art as expression, similarly argues for an understanding of the response to art as simultaneously emotional, intellectual, and imaginative: "appreciation of art requires active engagement with the work, involving acts of imagination and intellect through which a member of the audience recreates in his own mind the emotion which the work expresses" (Lewis 1995, 212). Lewis argues that an artist expresses a community's emotions, and continues: "Ideally, then, the artist must be at one with his audience, with, that is, the members of his community. He must participate in their weal and woe; experience their joys 
and sorrows, triumphs and disasters; share their concerns, interests, hopes, fears, etc." $(1995,212)$. He argues that in encountering an artwork the audience will "realize this is how they see things, how they feel about things, that these are their attitudes" (212).

For Lewis, art confirms who "we" are, and he therefore must view society as a homogeneous group. Even if Lewis saw society as a whole and audiences for art as diverse, he would have to regard each artwork as capable of addressing an audience which was itself homogeneous in values, beliefs, and experiences. On this view an artist could only relate to an audience which shared his or her views, values, and concerns. This seems entirely too cozy to me, and is reminiscent of Richard Rorty's insistence that art shapes "us" and confirms who "we" are. ${ }^{17}$ This view supposes that individuals do not belong to multiple communities, or, if we do, that we can only communicate to one community at a time. Moreover, this communication would be problematic based on the extent to which either the artist's or the audience member's other socio-identities would lead him or her not to be able to fully share the other's views, values, beliefs, joys, and sorrows. Finally, this view suggests that ultimately art does not transform but merely reinforces how things are seen and felt. Carroll similarly suggests that most artworks would "activate pre-existing" moral understandings (Carroll 1996, 230).

In contrast, I believe that while artworks must connect with their audiences on a variety of levels in order to be effective and affective, this does not mean that members of the work's audience must be strongly similar either to the artist or to each other. Against Lewis, I argue that what is so potentially powerful about art is the way some artworks can both alienate us and connect to us. Art can therefore help us be prepared to initiate more direct encounters with others in which we are receptive and prepared to be both different and the same.

Artworks can convey meaning both when we share many experiences with the artist and when we do not. Moreover, initial points of contact can be a jumping-off ground for understanding difference. Common experiences of being affected by one's socio-identities, of feeling alternately enriched and constrained by them, of feeling torn between different socio-identities, can help audiences relate to artists' works. These common experiences or shared features can then allow audiences to understand how different socio-identities are experienced differently, and to realize that individuals should not be reduced to one aspect of their identity. Hence, as Matthew Kieran argues, through encouraging us to be more imaginative, "An artwork may encourage us to consider and to become open to people, dilemmas, and states of affairs we might otherwise have dismissed out of hand" (Kieran 1996, 338).

Martha Nussbaum's position is close to my own. Although Nussbaum makes her arguments of behalf of works of literature, she holds, as do I, that works of art can have a deep moral impact on their audiences, and that this 
impact is often not incidental to the works, but due to the way in which they replace our habitual ways of looking at the world with more lively and more ambiguous metaphors. Nussbaum's favorite examples of this power of art to cut "through the blur of habit and the self-deceptions habit abets" come from the novels of Henry James, and rely on James's description of his own artistic endeavors in his Preface to The Golden Bowl (Nussbaum 1998, 343; see also Nussbaum 1985).

James teaches us, according to both James and Nussbaum, to avoid reliance on habitual thinking, abstract principles, and "standing terms" which in themselves are "a recipe for obtuseness" (Nussbaum 1985, 521; see also 519). What he gives us is not an extractable moral lesson-it "could not be captured in any paraphrase that was not itself a work of art" $(1985,521)$. Instead James provides a kind of moral knowledge which is "seeing a complex concrete reality in a highly lucid and richly responsible way; it is taking in what is there, with imagination and feeling" (521).

In many respects I agree with Nussbaum's analysis of the power of literature (which I attribute more broadly to art). I share her view that to write of the moral power of art is not to convey the view that art functions as a moral peppill. ${ }^{18}$ I also share her view that art can be morally and politically powerful because of the way it can awaken our imaginations and shake us loose from the power of stale and oppressive habits. Finally, we both agree that works of art exemplify "the cognitive role of the imagination and emotions in bringing us into contact with the complexity of our own lives and the lives of others" (Nussbaum 1998, 348).

However, I find her to go too far in two respects. My first disagreement is with her equation of moral attention and artistic attention, particularly insofar as she suggests that both involve a "determination to be guided by the tender and gentle emotions, rather than the blinding, blunt and coarse" $(1985,526)$. When we shake free from blunt and stale ways of looking at things, it is by no means clear that we will end up with one new, shared, lucid way of looking at things, let alone a tender and egalitarian approach. Nussbaum writes that "literature of a carefully specified sort can offer valuable assistance ... by both cultivating and reinforcing valuable moral abilities" (1998, 346). My disagreement here is a subtle one. While I think that the outcome of this liberation from habit may be morally or politically valuable, I think that no matter how "carefully specified" the works of art are, we cannot predict whether or not our response will be a morally or politically progressive one.

My second disagreement is related and has to do with her realism, even though she writes that the "realism in question is 'internal' and human; its raw material is human social experience, which is already an interpretation and a measure" $(1985,528)$. Nussbaum suggests that both the artist, and the person who responds receptively to an artist's work, learn to see what is really there. Here Nussbaum makes a move similar to the one I criticized in my account of 
Kieran. I have argued that our response to an artwork cannot be said to lead to us seeing or interpreting the world in any one particular, determinate way. Additionally, I suggest that an artwork does not so much reveal a truth as it does encourage us to leave behind rigid and potentially harmful habitual ways of thinking and feeling.

What happens when we shake off our stale ways of looking at things, or begin to look at issues and ideas we had not previously considered, cannot be predicted. We cannot predict the outcome of any conversations we have with another, when we are determined, throughout the conversation, to refuse to be guided by preordained rules. So, too, we cannot say in advance, nor can the artist, what will be the outcome of the imaginative explorations stimulated by our encounter with a vivid and thoughtful work produced by an imagination other than our own.

Art can start an encounter with another, and it can destabilize our terms of reference governing that encounter. To this extent it may enhance the possibilities that we will emerge from that encounter with changed beliefs and attitudes-but we cannot predict where those changes will take us. For instance, a person may emerge from an encounter with Gibson's painful exploration of her mixed loyalties and identifications in Flag with the (perhaps rueful) conclusion that Gibson needs to identify more strongly with some of those identities and reject others-either for the good of herself or the good of some of those groups. By contrast, another member of her audience may be moved to work towards changing the constitution of the various groups. A third audience member may be moved to self-centered reflections on her own diverse socio-identities, and may leave behind more concrete concern with Gibson's unique situation.

While contact with artworks can never replace more direct encounters with others who differ from us along multiple social dimensions, they can help prepare us for more sensitive contacts with others. When we respond to an artwork we are in contact with another, and we can let the other "speak" to us and attempt to "listen." There are no constraints on our response, and no way to guard against misinterpretation, which can be dangerous, but this may also help us tolerate ambiguity and ambivalence. When we respond to art we are often prepared to be both alienated and moved, disoriented and intrigued. We do not feel impelled either to dismiss the work as too different from us, or cover over its differences from us. Both of these moves are too often characteristic of social encounters where we do not feel kinship with the other, and therefore do not feel at ease.

Because in our responses to art we are prepared to be less goal-directed, partly because of the complexity of our responses, partly because of conventions that influence our approach to artworks, we are less inclined either to reject the work and its artist or to set the artist up as an authority on the basis 
of her experiences, conceived as entirely alien from our own. Moreover, when we respond to artworks, we focus on what the art reveals about ourselves as well as what it reveals about others. This may sound self-indulgent, but it can facilitate an increase in critical social consciousness by making us aware simultaneously of our own socio-identities as well as those expressed or explored in the artwork. To the extent that receptive response to an artwork involves an imaginative encounter with an other, it may therefore help prepare us for more direct encounters with others, and in particular lead us to expect them to be complicated in similar ways by experiences of both difference and connection, with accompanying powerful emotions.

\section{THE AudienCE FOR FEMINIST ARTWORKS THAT ADDRESS DIVERSE SOCIO-IDENTITIES}

While artworks can be powerful, I still need to address the question of who are most likely to be affected by such artworks. First of all, and most obviously, only people who have access to these works have any chance of being affected by them. For this reason many socially conscious artists have begun to focus on issues of accessibility. The following are all important factors in determining the accessibility of artworks to a broad and diverse audience: the hours a museum or gallery is open, its proximity to public transit, the cost of attendance, whether alternative and more popular locations are available for displaying the work ${ }^{19}$ whether works are easily portable and reproducible, where publicity for the art is targeted and in which languages it is available.

Beyond questions of whether art is accessible, there are also important issues concerning who might be interested in viewing artworks in general or artworks like these in particular, and what is required to understand them. We can work to broaden this audience, in part through arts education in schools, and in part by working with particular communities. For instance, Henry Tsang and Lorraine Chan's work with the Chinese Cultural Centre in Vancouver provided an audience of Chinese Canadians, many of whom were not independently interested in either the arts or contemporary arts, to artists of Chinese ancestry working with "ideas of heritage and authenticity" and "displacement, otherness, and racism" (Tsang 1995, 222). Moreover, the curators' work with the Chinese Cultural Centre led to coalition building with other community and cultural centers in Vancouver. This coalition building eventually led to the intercultural exhibit Racy Sexy (1991), which "examined how issues of race, culture and sexuality are interwoven in contemporary experience" (Tsang 1995, 229).

Tsang and Chan's experiences suggest that works like these are most likely to be effective with an audience whose members have already some initial interest in the subjects of identity and group differences. This audience 
would include people who have experienced clashes in their group memberships or socio-identities, and people who are "well meaning," in that they already seek to respect difference and to work towards pluralism. Both groups might, through their exposure to these artworks, gain more concrete understanding of themselves and others, and an awareness of the operation of power and various manifestations of inequality.

This is not a fixed group, in that it can be broadened. It can also be artificially narrowed by art critics or curators who think of identities as fixed and singular. Judith Wilson critiques and gives an example of this kind of reductive approach to the works of the U.S. Black feminist artist Alison Saar. Judith Wilson notes that Saar's works won a great deal of praise, but some critics like Donald Kuspit and Ellen Lee Klein thought she wasn't Black enough to be authentic in her art-making. Wilson observes,

Having noted the sculptor's racial identity and dubbed her "a serious student of black American culture and art history," Donald Kuspit, for example, went on to accuse Saar of "giving us a nostalgic look at something she has experienced only secondhand." Similarly, a review by Ellen Lee Klein charged Saar with having "absorbed too much of the image of black culture as seen by white culture so that her recreated imagery does not always directly reflect the black experience." Such commentary is symptomatic of a type of critical apartheid in which artists of color are condemned as "inauthentic" or "unoriginal" if they tap into aesthetic sources beyond their designated ethnic turf, while white artists' tendencies to raid the aesthetic cookie jars of the world go blithely unchallenged! (Wilson 1994, 64)

Moreover, Klein and Kuspit fail to recognize the extent to which Saar is exploring her own diverse socio-identities in her work. The demand that an artist's work "directly reflect the black experience" assumes both that there is such a thing as "the Black experience," homogeneous within itself, and that an individual either is an authentic representative of that experience, or that she has no real ties to and identification with Blacks as a social group. It is important that we challenge these assumptions if we are both to understand and to appreciate the aesthetically and politically significant work being done by feminist artists today.

In conclusion, I hope to have shown at this point that some feminist artworks can be a valuable resource not only for understanding the self as itself internally heterogeneous and shaped by socio-cultural forces and identifications, but also for understanding how our relations with others are negatively affected by failure to understand both their similarities and their differences from us. Because art affects us on many levels simultaneously, our experiences 
of artworks can be a particularly powerful force motivating us to seek to learn from and work with others who are different from us to work towards a more pluralistic society.

\section{NOTES}

1. I am not claiming that this "instrumental" value is either the only or the most important reason to appreciate feminist art-making practices and feminist artworks.

2. This work is available on the web at www.interaccess.org/iceflow/bojagi.htm

3. This work is available on the web at www.hws.edu/ laughter/12a.html

4. These images are available on the web at www.dialnsa.edu/i_galler/gallery/ works/images/simpson/simpson.html

5. This image is available on the web at www.sonoma.edu/classes/mams219/ ArtProject/SecB/MayanB

6. Images of her work, but not this particular work, are available on the web at: www.schoolnet.ca/collections/waic/ccar/ccar.htm

7. See Mullin (1995).

8. See Crenshaw (1994) for an excellent account of the way in which elision of intragroup differences puts an extra burden on women of color, causing women of color to have to split their political energies between groups neither of which reflects the ways in which their identities as women and as people of color are not additive but, in Crenshaw's metaphor, intersectional.

9. Some may worry that the attempt to empathize involves inappropriate assumptions that the other is just like the self. Trina Grillo and Stephanie M. Wildman warn us of the dangers of drawing analogies between our own situation and those of others, particularly when we seek to connect to others on the basis of shared pain or oppression. Such empathy, based on seeing the other as like the self, may lead the privileged to appropriate the pain of others and to seek to "take back the center" (Grillo and Wildman 1995, 173). The authors note that spending some "distinct recognition time" on both racism and sexism, for instance, can be a salutary corrective. Babad, Birnbaum, and Benne's methodology avoids this danger, I would argue, and shares in the advocated remedy, because of the extent to which each person is encouraged to see the ways in which others are both like and unlike the self.

10. This is sometimes referred to as increasing one's cultural competency, and activities with this aim may be called cultural competency training, diversity training, or multicultural training. See, for example, Ancis $(1998,134)$. I find it more valuable to refer to increasing one's critical social consciousness, because this avoids the assumption that a socio-identity is necessarily reflective of a culture, conceived of as a homogeneous way of life. See Appiah (1997) for an incisive account of the way the term "culture" may be misapplied when used to refer to all of our social identities. The phrase "diversity training" avoids this danger, but can sound as if all we need to do is become more aware of diversity, rather than also becoming aware of and seeking to oppose oppressive social practices. 
11. See Wicke (1992) for a criticism of this conception of difference within the self.

12. See Alcoff and Gray (1993) for an account of how "expertise" can and has been used to disempower survivors of sexual abuse. The authors note, however, that they are "not arguing that (non-survivor) experts cannot contribute to the empowerment and recovery of survivors. This contradicts our own experience and those of nearly every survivor we know. Our point is that, as we begin to break our silences, we must be wary of helping to create a public discursive arena that confers an a priori advantage on the expert's analysis and credibility over the survivor's" $(1993,284)$.

13. This point is stressed in many of the essays in the excellent volume Racism in the Lives of Women: Testimony, Theory, and Guides to Antiracist Practice (Adleman and Enguídanos, 1995). See, especially, Holzman (1995), Espin (1995), and Christensen (1995). Christensen in particular develops a model of cross-cultural awareness development "whereby an individual is enabled to interact with someone of a different racial, cultural, or ethnic background with authenticity, respect, openness, and acceptance" with strong similarities to the method outlined by Babad, Birnbaum, and Benne. Christensen does not focus on increasing awareness of gender differences because she presupposes a feminist therapist focused on treating women patients (Christensen 1995, 212).

14. In an interesting twist on this method, the University of Hawaii at Manoa, in its Expanded Arts Foundation class, has its students begin with a "Cross-Cultural Lens" project whereby two art students, who have contrasting social backgrounds or genders exchange information about their backgrounds, and do intensive research into those backgrounds before making a work of art together that reflects that exchange. See Wood (1995) for an account of this project.

15. As I use the term, the "imagination" is not limited to our capacity to conjure up mental images, but involves our larger capacity to think creatively.

16. For an elaboration of the ways in which some non-feminist art theories share feminist art theories' opposition to formalism (and for an account of why they are not feminist) see Mullin (1996).

17. See, for instance, Rorty (1989).

18. Nussbaum (1998) is a response to Posner (1997), which falsely characterizes Nussbaum's view in this way.

19. The increasing availability of images through the world wide web, including images of feminist works of art, is relevant here. Even though it can be difficult to capture the full experience of a work, particularly when these works of art are multimedia installations, many web sites of galleries and artists have been quite innovative in responding to some of these challenges.

\section{REFERENCES}

Adleman, Jeanne, and Gloria M. Enguídanos, eds. 1995. Racism in the lives of women: Testimony, theory, and guides to antiracist practice. New York: Harrington Park Press. 
Alcoff, Linda, and Laura Gray. 1993. Survivor discourse: Transgression or recuperation. Signs 18 (2): 260-90.

Ancis, Julie R. 1998. Cultural competency training at a distance. Journal of Counseling and Development 76 (2): 134-43.

Anderson, James C., and Jeffrey T. Dean. 1998. Moderate autonomism. The British Journal of Aesthetics 38 (2): 150-67.

Antony, Louise M. 1993. Quine as feminist: The radical import of naturalized epistemology. In A mind of one's own: Feminist essays on reason and objectivity, ed. Louise M. Antony and Charlotte Witt. Boulder: Westview Press.

Appiah, K. Anthony. 1997. The multiculturalist misunderstanding. The New York Review of Books 44 (15): 30-35.

Babad, Elisha Y., Max Birnbaum, and D. Kenneth Benne. 1983. The social self: Group influences on personal identity. Beverly Hills: Sage Publications.

Brand, Peggy. 1995. Revising the aesthetic-nonaesthetic distinction: The aesthetic value of activist art. In Feminism and tradition in aesthetics, ed. Peggy Brand and Carolyn Korsmeyer. University Park: The Pennsylvania State University Press.

Brand, Peggy and Carolyn Korsmeyer, eds. 1995. Feminism and tradition in aesthetics. University Park: The Pennsylvania State University Press.

Carroll, Noel. 1996. Moderate moralism. The British Journal of Aesthetics 36 (3): 223-39.

Christensen, Carole Pigler. 1995. Cross-cultural awareness development: An aid to the creation of anti-racist feminist therapy. In Racism in the lives of women: Testimony, theory, and guides to antiracist practice, ed. Jeanne Adleman and Gloria M. Enguídanos. New York: Harrington Park Press.

Crenshaw, Kimberlé. 1994. Mapping the margins: Intersectionality, identity politics, and violence against women of color. In The public nature of private violence, ed. M. A. Fineman and R. Hykitiuk. New York: Routledge.

De Lauretis, Teresa. 1990. Rethinking women's cinema: Aesthetics and feminist theory. In Issues in feminist film criticism, ed. Patricia Erens. Bloomington: Indiana University Press.

Espín, Olivia M. 1995. On knowing you are the unknown: Women of color constructing psychology. In Racism in the lives of women: Testimony, theory, and guides to antiracist practice, ed. Jeanne Adleman and Gloria M. Enguídanos. New York: Harrington Park Press.

Felski, Rita. 1995. Why feminism doesn't need an aesthetic (and why it can't ignore aesthetics). In Feminism and tradition in aesthetics, ed. Peggy Brand and Carolyn Korsmeyer. University Park: The Pennsylvania State University Press.

Freire, Paolo. 1973. Education for critical consciousness. New York: Continuum Press.

Grillo, Trina, and Stephanie Wildman. 1995. Sexism, racism, and the analogy problem in feminist thought. In Racism in the lives of women: Testimony, theory, and guides to antiracist practice, ed. Jeanne Adleman and Gloria M. Enguídanos. New York: Harrington Park Press.

Hartsock, Nancy C. M. 1996. Theoretical bases for coalition building: An assessment of postmodernism. In Feminism and social change: Bridging theory and practice, ed. Heidi Gottfried. Chicago: University of Illinois Press.

Holzman, Clare. 1995. Rethinking the role of guilt and shame in white women's 
antiracism work. In Racism in the lives of women: Testimony, theory, and guides to antiracist practice, ed. Jeanne Adleman and Gloria M. Enguídanos. New York: Harrington Park Press.

Jennings, Todd. 1995. Developmental psychology and the preparation of teachers who affirm diversity. Journal of Teacher Education 46 (4): 243-251.

Kieran, Matthew. 1995. The impoverishment of art. British Journal of Aesthetics 35 (1): 15-26.

1996. Art, imagination, and the cultivation of morals. The Journal of Aesthetics and Art Criticism 54 (4): 337-51.

Lewis, Peter, 1995. Art, the community's medicine. British Journal of Aesthetics 35 (3): 205-16.

Longino, Helen E. 1993. Essential tensions-phase two: Feminist, philosophical, and social studies of science. In A mind of one's own: Feminist essays on reason and objectivity, ed. Louise M. Antony and Charlotte Witt. Boulder: Westview Press.

Marcus, Laura. 1992. Feminist aesthetics and the new realism. In New feminist discourses, ed. Isobel Armstrong. London: Routledge.

Mead, George Herbert. 1962. Mind, self, and society. Ed. Charles W. Morris. Chicago: University of Chicago Press.

Mullin, Amy. 1995. Selves, diverse and divided: Can feminists have diversity without multiplicity? Hypatia 10 (4): 1-31.

- 1996. Art, politics and knowledge: Feminism, modernity and the separation of spheres. Metaphilosophy 27 (1/2): 118-45.

Nussbaum, Martha. 1985. Finely aware and richly responsible: Moral attention and the moral task of literature. The Journal of Philosophy 82 (10): 516-29.

- 1998. Exactly and responsibly: A defense of ethical criticism. Philosophy and Literature 22 (2): 343-65.

Phillips, Patricia C. 1995. Peggy Diggs: Private acts and public acts. In But is it art? The spirit of art as activism, ed. Nina Felshin. Seattle: Bay Press.

Pollock, Griselda. 1987. Feminism and modernism. In Framing feminism: Art and the women's movement 1970-1985, ed. Roszika Parker and Griselda Pollock. London: Pandora Press.

Posner, Richard A. 1997. Against ethical criticism. Philosophy and Literature 21 (1): $1-27$.

Rich, Ruby. 1990. In the name of feminist film criticism. In Issues in feminist film criticism, ed. Patricia Erens. Bloomington: Indiana University Press.

Rorty, Richard. 1989. Contingency, irony and solidarity. Cambridge: Cambridge University Press.

Stott, Annette. 1998. Transformative triptychs in multicultural America. Art Journal 57 (1): 55-63.

Tsang, Henry. 1995. Inside, outside, upside down: In search of cultural space with the Chinese Cultural Centre in Vancouver. In Questions of community, ed. Daina Augaitis, Lorne Falk, Sylvie Gilbert, and Mary Anne Moser. Banff: Banff Centre Press.

Vogel, Lise. 1988. Fine arts and feminism: The awakening consciousness. In Feminist art criticism: An anthology, ed. Arlene Raven, Cassandra Langer, and Joanne Frueh. New York: Harper Collins. 
Wicke, Jennifer. 1992. Postmodern identities and the politics of the (legal) subject. boundary 219 (2): 10-33.

Wilson, Judith. 1994. Will the "new internationalism" be the same old story: Some art historical considerations. In Global visions: Towards a new internationalism in the visual arts, ed. Jean Fisher. London: Kala Press.

Wood, Patricia. 1995. Swap meet: A cross-cultural lens project. Art Journal 58 (11): $87-88$. 